\title{
Effect of Machine Replacement Cost on the Profitability of Feed Mill Industries in Ibadan Metropolis
}

\author{
Salawu, M.B* and A.M Rufai** \\ *Federal College of Animal Health and Production Technology, Moor Plantation Ibadan, Nigeria \\ **Department of Agricultural Economics, University of Ibadan, Nigeria.
}

\begin{abstract}
Inadequate and imbalance nutrition has been identified as one of the factors militating against livestock and poultry production in the country as most farmers depend on compounded feed to supply the nutrients required for their animals and birds to grow well. However no matter how good a machine used for feed compounding is, its parts or components wears out with age. The replacement of machine could be cost effective if it is done in time and in a proper way. This study attempted to examine the effect of machine replacement cost on the profitability of feed mills in Ibadan metropolis. Multistage sampling technique was used to select respondents for the study and data were collected with the aid of questionnaire. The study was analyzed using descriptive statistics, gross margin analysis, replacement model analysis and regression analysis. The results of the study revealed that majority of the respondents were male and married with tertiary education. The mean age of the respondents was 4lyears. The study identified hammermill/ grinder, mixer and scale as the most common machines used by the millers and the average age of the machines is six years. The machines had a total replacement cost of $\$ 909,095.30$ and the feed mills had an average profit of $\$ 63,100,000$ per annum. The regression results revealed that the machine replacement cost had a positive relationship with the profitability of feed mills. Other variables namely marital status, education of the respondents, ethnicity, credit access and membership of association were also found to be significant. The study thus recommended the adequate maintenance and timely replacement of machines as they increase the productivity and profitability of feed mills.
\end{abstract}

Keywords: Feed-mill, Machine, Replacement Cost, Profitability

\section{Introduction}

Agriculture has played a dominant role in improving the economy of every nation in the world in which Nigeria is not an exemption. The contribution of its livestock subsector cannot be overemphasized. Even though the sector has contributed to food security and the development of the nation (Bamaiyi, 2013), its production has been hindered by several factors such as inadequate finance, problem of transportation, incidence of animal diseases, lack of government incentives, and high cost of animal feed among others. Research has linked the success in animal husbandry to a good combination of animal rearing and feed production because feeding constitutes about 65-68 percent of cost of rearing animals especially poultry (Uba, 2013).

Odunsi et al., (2008) opined that out of the 95\% daily feed requirement of animals, feed mills can produce a compact feed that can satisfy about $90 \%$ of the daily feed requirement. This signifies the important role played by feed mills in agriculture and fisheries development and in ensuring food security by providing inputs to the livestock, poultry sector as well as the aquaculture sector in Nigeria. It produces formulated high quality feeds such as broiler starter, broiler finisher, grower mash, layer mash, chick mash, pelletized fish meal among others to enhance the growth of the animals and increase the revenue that accrue to the farmers. The impact of the industry cannot be felt on viability and profitability alone but also on the productivity and competitiveness of the livestock subsector (Esplana et al., 2005). Ademuyiwa (2004) in his submission opined that aside from the contribution of feed mill industry to feeds and feedstuff production, the industry also creates market for intermediate and fiscal product of the agricultural sector as well as enhancing exchange research into new agricultural products as feedstuff materials.

In compounding high quality feed for farmers, a feed mill plant has the capacity of producing 5 tonnes per day of animal feed with the use of machines which are mostly locally fabricated and operated either manually or used with electricity. The machines commonly used are the hammer mill/grinder, conveyor, mixer, scale, sealing machine among others. The use of these machines year in and year out brings about the wear and tear of the different parts of the machines and leads to loss of efficiency in the level of production. The decline in the level of output generated in turn causes economic decline on the part of the industry. In order to put the machines to the desired level of production, the replacement of the machines becomes necessary.

It is generally believed that as time moves on, the parts of machines are being worn out and the cost of maintenance and operation is bound to increase year after year. The resale value of the item goes on diminishing with the passage of time. The depreciation of the original equipment is a factor, which is responsible not to 
favour replacement but the capital is being spread over a long time leading to a lower average cost. Thus there exists an economic trade-off between increasing and decreasing cost functions. It is however better to strike a balance between the two opposing costs with the aim of obtaining a minimum cost. The problem of replacement is to determine the appropriate time at which a remedial action should be taken so as to ensure maximum productivity. The aim of tackling any replacement problem is either to minimize cost or maximize profit. Other factors such as inadequacy, technical and economic obsolescence may also bring about replacement of equipment or machines.

A replacement decision in any industry is very important. This is because replacement decision will help an industry to monitor the economic and technological progress of the industry, prevent hasty replacement which can lead to draining of operating capital of the industry and avoid increased production cost and loss of competiveness due to postponement of replacement decision.

\section{Problem Statement}

Inadequate and imbalanced nutrition has been identified as one of the factors militating against livestock production in the country (Ango-Abdullahi, 2011). This is because most livestock farmers depend on compounded feed to supply the nutrients required for their animals to grow well. The quality and quantity of feed available to such farmers is often partly dependent on the efficiency of the machines used by feed mill industries to compound feed. Blanchard (2000) opined that no matter how good a machine is, its parts or components wears out with age therefore replacement of machine is a very good decision if it is done in time and in a proper way. Every machine has a productive age after which the machine is unproductive for any industry (Akinnuli, 2014). Deterioration on any part of machine can lead to excessive operation cost, high maintenance cost and another cost of purchase for a new machine if machine is to be replaced (Tadic et al, 2010). Various reasons have been attributed to machine replacement decision in Nigeria and Akinnuli (2009) related it to scarcity of spare parts, excessive operation and maintenance cost. Bethune (1998) attributed replacement decisions to reduction in the output capacity of the machine. High frequency of failure and high cost of penalties incurred as a result of material wastage and clean ups are also important factors identified in literature (Gupta and Hira, 2012). Another factor identified by Akinnuli 2011 is the increased downtime of machines due to the unavailability of specialists with the technical knowhow to repairs such machines. The efficiency of feed mill industry is very important to the livestock sector because the sector depends on the feed mill industry to feed its stock. Faulty machines in feed mills lowers feed production which has negative impact on the production of farmers. This study therefore examines the effect of machine replacement cost on the profitability of feed mill industry in the study area.

\section{Objectives of the Study}

The general objective of this paper is to examine the effect of machine replacement cost on the profitability of feed mill while the specific objectives are:

$>$ To determine the optimum replacement cost and period of machines used by feed mill industries in the study area.

$>$ To estimate the profit of feed mill in the study area.

$>$ To examine the effect of machine replacement cost on the profitability of feed mill.

\section{Replacement Models}

\section{Theoretical Background}

Olayemi and Onyenwaku (1999) identified two major models in a replacement problem. The models are cost minimization replacement problems and profit maximization replacement problems. The cost minimization replacement model is usually applied to durable capital assets like machines whose cost of maintenance and repair may become so high such that its discounted total cost is higher than the cost of buying a new one while the profit maximization replacement model is a problem of maximization of a future stream of net revenues from an existing enterprise or asset. The profit maximization model can be applied to replacement of permanent crops plantation or replacement of birds in the poultry industry. In the cost minimization replacement problem, three situations may arise; these are (i) replacement of items whose maintenance cost increases with time and the value of the money remain constant during the period. (ii) replacement of items whose maintenance cost increases with time and value of money also changes with time. (iii) group Replacement policy.

All these situations are based on the assumptions that the entrepreneur is rational and believe he should make profit in the use of equipment for an infinite number of future periods. The model also assumed that once an equipment is brought into use, there should be continued profitability of use and when the equipment is due for replacement, it would be replaced with an identical one. 
The model is thus represented with the equations below if there is no allowance for salvage value of equipment/machine.

Or

$$
P_{n}=C+R_{1}+R_{2} /(1+r)+R_{2} /(1+r)^{2+\cdots R_{2}} /(1+r)^{n-1}
$$

$$
P_{n}=C+\sum_{i=1}^{n} R_{t} /(1+r) i-1
$$

Where $P_{n}=$ Total present value of all the future costs over a period of $\mathrm{n}$ years.

$R_{t}=$ The total running or maintenance cost of equipment in time $\mathrm{t}$.

$\mathrm{r}=$ The discount or interest rate.

$\mathrm{n}=$ Optimum replacement period.

$\mathrm{C}=$ Initial cost of purchase of the machine/equipment.

However, if allowance is given for the salvage value of equipment after a certain period $t$ then the model becomes

$$
P_{n}=C-S V^{t}+\sum V^{n} R_{t}
$$

Where $S V^{t}$ is the discounted salvage present value of the salvage value of equipment/machine at the end of year $\mathrm{t}$. The decision rule is to replace the equipment/machine when

Or

$$
\frac{\left(1-V^{n}\right)}{1-V} R_{n+1}>P_{n} \ldots \ldots \ldots \ldots(4)
$$

$$
R_{n+1}>P_{n} \frac{(1-V)}{\left(1-V^{n}\right)}
$$

\section{Study Area}

\section{Methodology}

The study was conducted in Ibadan the Oyo state capital. The state is located in the south-west geopolitical zone of Nigeria. The state was created in February 1976 and it has 33 local government areas. Eleven out of the local government areas are located within Ibadan. The city is the centre of administration of the old western region with a population size of about two million. Ibadan is an urban city mostly dominated by the Yoruba though a sizeable number of people from different tribes and ethnic groups are found in the area.

The study was carried out in five local government areas in Ibadan. The local government areas are Egbeda local government, Ido local government, Oluyole local government, Ona -Ara local government and Akinyele local government.

\section{Sampling Technique}

Multistage random sampling technique was employed for this study. The first stage is the purposive selection of five local governments based on the large population of feed mill industries within them. The local government areas were Egbeda local government, Ido local government, Oluyole local government, Ona -Ara local government and Akinyele local government. Twenty- five questionnaires were administered in each local government area. The sample size for the study is one hundred and twenty five respondents. It should however be noted that only one hundred and one were found analyzable.

\section{Data Collection}

The data for the study were collected with the aid of a well structured questionnaire. The data collected include; socio-economic characteristics of the respondents, machinery information of the industry, cost and returns on the production of poultry feed among others. The study limited the respondents to feed millers which produced poultry feeds alone. This is because majority of the feed millers in the study area specialized in that kind of feed alone and compounded ruminant and fish feeds based on request by customers. The poultry feeds compounded by feed millers are broiler starter, broiler finisher, grower mash, layer mash and chick mash.

\section{Method of Data Analysis}

The data of this study were analyzed using descriptive statistics, Gross Margin analysis, replacement model analysis and multiple regression analysis. The descriptive statistics include frequency count, mean and percentages.

Gross Margin Analysis: The cost components of feed production such as cost of building/rentage, cost of feed ingredients, cost of electricity, cost of petrol/diesel, cost of transportation, bagging/packaging and other cost incurred in the production of poultry feeds were deducted from the revenue derived from the sale of poultry feeds to get the profit. Therefore

Total Cost $=$ Total Fixed Cost + Total Variable Cost. 
Revenue = Unit Price X Quantity of goods sold.

Profit $=$ Revenue - Total Cost.

Replacement Model: The study adapted the cost minimization replacement problem model which does not give allowance for the salvage value of the machine as shown in equation (1) and (2).

However, the cumulative $P_{n}$ in the replacement period $\mathrm{n}$ for each of the feed mills used in the study was used as a proxy for the replacement cost of the machine. This is because $P_{n}$ naira will take care of the purchase price of a new machine to replace the old machine in year n. It will also take care of the cost running and maintaining the machine for another $n$ year.

Multiple Regression Analysis: It is a statistical technique that shows the relationship between a dependent variable and two or more explanatory variables. The model of regression analysis is thus specified as

$$
Y=\beta_{0}+\beta_{1} X_{1}+\beta_{2} X_{2}+\cdots \beta_{n} X_{n}
$$

Where $Y=$ Profit of feed millers. $X_{1}=$ Sex. $X_{2}=$ Age (years) $X_{3}=$ Age $^{2} . X_{4}=$ Marital status.

$\mathrm{X}_{5}=$ Education. $\mathrm{X}_{6}=$ Ethnicity. $\mathrm{X}_{7}=$ Religion. $\mathrm{X}_{8}=$ Experience. $\mathrm{X}_{9}=$ Credit access.

$\mathrm{X}_{10}=$ Membership of Association. $\mathrm{X}_{11}=$ Machine replacement cost

\section{Result And Discussions}

The socio economic characteristics of the respondents shows that majority of the respondents $(90.10 \%)$ were male and about $9.90 \%$ were female. This implies that feed mill business is dominated by males and this may be attributed to the energy required for the business. The mean age was 41 years which implies that majority of the feed millers were still in their active working age. Majority of the respondents $(63.37 \%)$ had ages between 27 and 40 while few of them were aged between 41 and 50 (11.88\%).

Table 1: Socio-economic Characteristics of Respondents

\begin{tabular}{|c|c|c|c|}
\hline Variable & Frequency & Percentage & Mean \\
\hline \multicolumn{4}{|l|}{ Sex } \\
\hline Male & 91 & 90.10 & \\
\hline Female & 10 & 9.90 & \\
\hline \multicolumn{4}{|l|}{ Age (years) } \\
\hline $27-40$ & 64 & 63.37 & 41.32 \\
\hline $41-50$ & 12 & 11.88 & \\
\hline$>50$ & 25 & 24.77 & \\
\hline \multicolumn{4}{|l|}{ Marital Status } \\
\hline Single & 19 & 18.81 & \\
\hline Married & 82 & 81.19 & \\
\hline \multicolumn{4}{|l|}{ Education } \\
\hline No Formal Education & 6 & 5.94 & \\
\hline Primary & 17 & 16.83 & \\
\hline Secondary & 2 & 1.98 & \\
\hline Tertiary & 76 & 75.25 & \\
\hline \multicolumn{4}{|l|}{ Ethnicity } \\
\hline Yoruba & 96 & 95.05 & \\
\hline Igbo & 5 & 4.95 & \\
\hline \multicolumn{4}{|l|}{ Religion } \\
\hline Islam & 10 & 9.90 & \\
\hline Christian & 91 & 90.10 & \\
\hline \multicolumn{4}{|l|}{ Experience (years) } \\
\hline $1-5$ & 12 & 11.88 & 11.46 \\
\hline $6-10$ & 47 & 46.53 & \\
\hline $11-15$ & 23 & 22.77 & \\
\hline$>15$ & 19 & 18.81 & \\
\hline \multicolumn{4}{|l|}{ Access to Credit } \\
\hline Yes & 43 & 42.57 & \\
\hline No & 58 & 57.43 & \\
\hline \multicolumn{4}{|l|}{ Sources of Credit } \\
\hline Cooperative & 8 & 21.05 & \\
\hline Commercial Bank & 27 & 71.05 & \\
\hline Friends and Relatives & 3 & 7.89 & \\
\hline \multicolumn{4}{|l|}{ Amount Acquired ( } \\
\hline $200,000-400,000$ & 17 & 39.53 & 888,372 \\
\hline $500,000-900.000$ & 19 & 44.19 & \\
\hline $1,000,000$ and above & 7 & 16.28 & \\
\hline \multicolumn{4}{|l|}{ Association } \\
\hline Yes & 38 & 37.62 & \\
\hline No & 63 & 62.38 & \\
\hline
\end{tabular}

Source: Field Survey, 2015 
Most of the feed millers were married $(81.19 \%)$ with tertiary education $(75.25 \%)$. The mean year of experience was over 10years which implies that the feed millers were not new in the business. More than half of the respondents did not have access to credit however most of those that had got them from commercial banks. Less than $20 \%$ of the respondents had access to above one million naira as credit. This may be attributed to stringent rules associated with loan collection in most commercial banks. The table also shows that majority of the respondents did not belong to any association. Most of the respondents associated this to the lack of umbrella body bringing the feed millers together.

Table 2 shows the machinery information of respondents. The machines utilized by the feed millers are hammermill/grinder, conveyor, mixer, scale and sealing machine. Though not all feed mills used the five machines but the three commonly used are the hammermill/grinder, mixer and the scale. The specification for hammermill/grinder, conveyor and mixer are small, medium and large while the scale can either be manual or electrical. The study revealed that majority of the respondents $(69.31 \%)$ had the medium hammermill/grinder, while $13.86 \%$ had the large hammermill. About $6.93 \%$ had both small and large hammermill while $9.90 \%$ had both the medium and large hammermill. More than half of the feed mills surveyed did not have the conveyor machine. This is because these set of millers pour grinded feed ingredients from the hammer mill to the mixer manually. However, $26.73 \%$ of the feed millers had the medium conveyor while $1.98 \%$ and $15.84 \%$ had the small and large conveyor respectively. About $46.53 \%$ had the medium mixer, while about $23.76 \%$ and $15.84 \%$ had the medium mixer and small mixer, respectively. Also about $13.86 \%$ had both small and medium mixer. Majority $(67.33 \%)$ of the feed mills use the manual scale, $11.98 \%$ use the digital/electrical scale while $20.79 \%$ used both manual and electrical scale. Majority of the feed mills did not use sealing machines (78.22\%), they made use of ropes and twine while only $21.78 \%$ had sealing machine for packaging their product. The machines had an average age of the machines is six years while the sealing machine had an average age is five years.

Table 2: Machinery Information of Respondents

\begin{tabular}{|l|l|l|}
\hline Machine & Frequency & Percentage \\
\hline Hammer mill/grinder & & \\
\hline Medium & 70 & 69.31 \\
\hline Large & 14 & 13.86 \\
\hline Small and Large & 7 & 6.93 \\
\hline Medium and Large & 10 & 9.90 \\
\hline Conveyor & & \\
\hline No conveyor & 53 & 52.48 \\
\hline Small & 2 & 1.98 \\
\hline Medium & 27 & 26.73 \\
\hline Large & 16 & 15.84 \\
\hline Medium and large & 3 & 2.97 \\
\hline Mixer & & \\
\hline Small & 16 & 15.84 \\
\hline Medium & 47 & 46.53 \\
\hline Large & 24 & 23.76 \\
\hline Small and Medium & 14 & 13.86 \\
\hline Scale & & \\
\hline Digital/Electrical & 12 & 11.98 \\
\hline Manual & 68 & 67.33 \\
\hline Both & 21 & 20.79 \\
\hline Sealing Machine. & & \\
\hline No sealing machine & 79 & 78.22 \\
\hline Availability of sealing machine & 22 & \\
\hline Average Age of Machine (years) & & \\
\hline Hammer mill/grinder & 6.29 & \\
\hline Conveyor & 6.27 & \\
\hline Mixer & 6.16 & \\
\hline Scale & 6.10 & \\
\hline Sealing Machine & 4.98 & \\
\hline & & \\
\hline & & \\
\hline & & \\
\hline & & \\
\hline & & \\
\hline & & \\
\hline & & \\
\hline & & \\
\hline & & \\
\hline
\end{tabular}

Source: Field Survey, 2015

Table 3 shows the machinery cost information. The table revealed that the average cost of hammermill/grinder, conveyor, mixer, scale and sealing machine are N180,459.20; N113,125; 240,714.30; 82,775.51 and 40,774.19 respectively. The table also shows the average maintenance cost for each of the machine however the nature of maintenance carried out is dependent on the type of machine. The type of problems that are peculiar with hammermill/grinder and the mixer are the breakdown of electric motor and changing of belts. The cost of repair depends on how severe the problem is and the bargaining power of the feed 
miller as technicians charge based on prevailing economic situation. The routine maintenance carried out on scale is servicing. Most of the feed millers do this at least once in a year. In this study, the average maintenance cost was derived by aggregating the cost of maintenance of similar machines that have been used for the same number of years divided by the number of years of use. The average cost of maintenance were N67,468.87; N150,613.33 and N95,000 for hammermill/grinder that had been used for 1-5, 6-10 and 11-15 years respectively. Conveyor had an average maintenance cost of $\$ 17,770.83$, $\$ 31,166.66$ and $\$ 84,000$ for the three groups respectively while the average maintenance cost of the mixer was $\$ 64,042.92$, $132,739.99$ and $\$ 138,500$. Scale had an average maintenance cost of $\$ 21,696.07$; $\$ 46,626.67$ and $\$ 62,000$ for 1-5, 6-10 and 11-15 years respectively while sealing machine had an average maintenance cost of $\$ 2,681.74$ and $\$ 15,266.67$ for 1-5 and 6-10 years respectively. In this study, the replacement cost is referred to as the average replacement cost as the average maintenance cost was used to compute the replacement cost. The study also assumed that the interest rate was $10 \%$. The result shows that the average replacement costs were $\$ 315,096.20$; $156,916.10$; $\$ 357,761.40, \$ 134,383.38$ and $\$ 47,415.38$ for hammermill/grinder, conveyor, mixer, scale and sealing machine respectively. The replacement cost for each machine was summed up to get the total machine replacement cost for a feed mill and the average of this was found to be $\$ 909,095.30$.

Table 3: Machinery Cost Information of Respondents.

\begin{tabular}{|c|c|c|c|}
\hline Variable & Cost (A) & Minimum & Maximum \\
\hline \multicolumn{4}{|l|}{ Average Cost of Machine } \\
\hline Hammer mill/grinder & $\begin{array}{l}180,459.20 \\
(147218.30)\end{array}$ & $50,000.00$ & $640,000.00$ \\
\hline Conveyor & $\begin{array}{l}113,125.00 \\
(75276.97) \\
\end{array}$ & $30,000.00$ & $250,000.00$ \\
\hline Mixer & $\begin{array}{l}240,714.30 \\
(194718.10)\end{array}$ & $50,000.00$ & $1,000,000.00$ \\
\hline Scale & $\begin{array}{l}82,775.51 \\
(64615.36)\end{array}$ & $10,000.00$ & $300,000.00$ \\
\hline Sealing Machine & $\begin{array}{l}40,774.19 \\
(21160.83) \\
\end{array}$ & $5,000.00$ & $80,000.00$ \\
\hline \multicolumn{4}{|c|}{$\begin{array}{l}\text { Average Maintenance cost of } \\
\text { Machine }\end{array}$} \\
\hline \multicolumn{4}{|c|}{ Hammer mill/grinder } \\
\hline $1-5$ & $67,468.87$ & $36,933.34$ & $75,085.00$ \\
\hline $6-10$ & $150,613.33$ & $62,400.00$ & $245,000.00$ \\
\hline $11-15$ & $95,000.00$ & $55,000.00$ & $140,000.00$ \\
\hline \multicolumn{4}{|l|}{ Conveyor } \\
\hline $1-5$ & $17,770.83$ & $4,500.00$ & $50,000.00$ \\
\hline $6-10$ & $31,166.66$ & $18,000.00$ & $42,000.00$ \\
\hline $11-15$ & $84,000.00$ & $84,000.00$ & $84,000.00$ \\
\hline \multicolumn{4}{|l|}{ Mixer } \\
\hline $1-5$ & $64,042.92$ & $26,600.00$ & $100,340.90$ \\
\hline $6-10$ & $132,739.99$ & $61,200.00$ & $273,000.00$ \\
\hline $11-15$ & $138,500.00$ & $44,000.00$ & $240,000.00$ \\
\hline \multicolumn{4}{|l|}{ Scale } \\
\hline $1-5$ & $21,696.07$ & $12,777.78$ & $36,363.65$ \\
\hline $6-10$ & $46,626.67$ & $22,000.00$ & $71,333.34$ \\
\hline $11-15$ & $62,500.00$ & $55,000.00$ & $70,000.00$ \\
\hline \multicolumn{4}{|l|}{ Sealing Machine } \\
\hline $1-5$ & $2,681.74$ & $1,028.57$ & $3,750.00$ \\
\hline $6-10$ & $15,266.67$ & $4,800.00$ & $21,000.00$ \\
\hline \multicolumn{4}{|c|}{$\begin{array}{l}\text { Average Replacement Cost } \\
\text { of Machine }\end{array}$} \\
\hline Hammer mill/grinder & $\begin{array}{l}315,096.20 \\
(201092.20)\end{array}$ & $76,506.04$ & $930,746.60$ \\
\hline Conveyor & $\begin{array}{l}156,916.10 \\
(73581.77)\end{array}$ & $50,078.52$ & $300,396.80$ \\
\hline Mixer & $\begin{array}{l}357,761.40 \\
(210143.7)\end{array}$ & $103,012.10$ & $1,209,156$ \\
\hline Scale & $\begin{array}{l}134,383.30 \\
(67518.72)\end{array}$ & $39,550.48$ & $360,846.6$ \\
\hline Sealing Machine & $\begin{array}{l}47,415.38 \\
(23784.66)\end{array}$ & $6,142.41$ & $92,549.08$ \\
\hline Total Replacement Cost. & $\begin{array}{l}909,095.30 \\
(500,036.6)\end{array}$ & $241,024.20$ & $2,366,992$ \\
\hline
\end{tabular}

Source: Field Survey, 2015 


\section{Result Of Cost And Return Analysis}

The costs and returns analysis shows that the costs of production in the feed mill business include cost of building/rent which had an average of about $\$ 2,135,198$. The cost of feed ingredient accounted for the highest percentage which is about $\$ 75,500,000$. Feed millers spent more on feed ingredients especially during the peak season when majority of these products were readily available. They invest huge capital by buying them in bulk and store in their warehouses. Most of the feed millers with warehouses also sold to their colleagues during the off season when the products were not readily available. An average of $\$ 357,206.50$ was spent on electricity and this was complimented with about $\$ 663,643.60$ spent on petrol/diesel. The high expense on petrol/diesel is attributed to erratic power supply experienced among feed millers. About $\$ 2,137,772$ and $\$ 232,290$ were expended on labour and transportation respectively, while about $\$ 91,896.55$ and $\$ 20,000$ were spent on bagging/packaging and other miscellaneous expenses. An average total cost of $\$ 89,000,000$ was expended by the millers. The total revenue was derived by multiplying the average tonnes of feeds produced by the average price of feed produced by each mill. This study concentrated on five poultry feeds which are broiler starter, broiler finisher, grower mash, layer mash and chick mash and average total revenue of the feed millers is N144,000,000. The profit was derived by subtracting the average total cost from the average revenue and it had an average of $\$ 63,100,000$ per annum among the respondents. Though, the result of the study also shows that some millers experienced losses but generally the enterprise was still profitable.

Table 4: Cost and Returns of Feed millers

\begin{tabular}{|c|c|c|c|}
\hline Variable & Amount (N) & Minimum & Maximum \\
\hline Total Revenue ( & $\begin{array}{c}144,000,000.00 \\
(64,200,000)\end{array}$ & $42,000,000.00$ & $294,000,000.00$ \\
\hline \multicolumn{4}{|l|}{ Costs } \\
\hline Building/Rent & $\begin{array}{c}2,135,198.00 \\
(3391433)\end{array}$ & $30,000.00$ & $12,000,000.00$ \\
\hline Feed Ingredients & $\begin{array}{l}75,500,000.00 \\
(196,000,000)\end{array}$ & $2,000,000.00$ & $700,000,000.00$ \\
\hline Cost of Electricity & $\begin{array}{r}357,206.50 \\
(739,565.20)\end{array}$ & $12,000.00$ & $3,000,000.00$ \\
\hline Cost of Petrol/diesel & $\begin{array}{l}663,643.60 \\
(1,022,813)\end{array}$ & $35,000.00$ & $4,500,000.00$ \\
\hline Labour. & $\begin{array}{r}2,137,772.00 \\
(3,481,533)\end{array}$ & $200,000.00$ & $13,400,000.00$ \\
\hline Transportation & $\begin{array}{r}232,290.00 \\
(268,598.50)\end{array}$ & $12,000.00$ & $905,000.00$ \\
\hline Bagging/packaging & $\begin{array}{c}91,896.55 \\
(97,620.38)\end{array}$ & $18,000.00$ & $300,000.00$ \\
\hline Others. & $20,000.00$ & $20,000.00$ & $20,000.00$ \\
\hline Total Cost & $\begin{array}{l}81,000,000.00 \\
(202000000)\end{array}$ & $2,426,000.00$ & $724,000,000.00$ \\
\hline \multicolumn{4}{|l|}{ Profit } \\
\hline Total Revenue - Total Cost & $\begin{array}{l}63,100,000.00 \\
(204,000,000)\end{array}$ & $-568,000,000.00$ & $274,000,000.00$ \\
\hline
\end{tabular}

Source: Field Survey, 2015.

\section{Regression Result Showing Effect Of Machine Replacement Cost On Profitability}

The regression analysis shows that $\mathrm{R}^{2}$ which is the measure of goodness of fit is 0.5155 ; this implies that the independent variables explained about $52 \%$ of the variations in the profit of feed millers. The unexplained percentage may be due to other factors that affect profitability that were not included in the model. The results show that marital status, education, ethnicity, access to credit, membership of association and machine replacement cost had a significant relationship with the profit of feed millers. Though age was not significant, further analysis shows that as the millers became old, their profit tend to decrease. Marital status was significant at $1 \%$, this may be due to the fact that majority of millers were married and had responsibilities to cater for. The availability of family labour could also assist in the business and increase the efficiency of production. Education was also significant at $1 \%$, this may be attributed to the fact that majority of the feed millers had tertiary education. Education makes the adoption of new technology easy thus influencing their profitability. Credit provides more capital to the business and more capital may translate to more profit. The result revealed that profit increased significantly with access to credit. Membership of association was also significant at $1 \%$, this implies that if feed millers were associated with groups they could acquire benefits as a team that would improve their business hence increase their profitability. The machine replacement cost also increased significantly with profit. This implies that as the profit increases, machine replacement cost also increase. This indicates that as the feed mill produces more feed, machines tend to experience breakdown or wear and tear which in turn increases the maintenance cost as well as the replacement cost. 
Table 5: Regression Result showing the Effect of Machine Replacement Cost on the Profitability of Feed mill

\begin{tabular}{|l|l|l|l|}
\hline Variable & Coefficient & t-value & P-value \\
\hline Sex & $\begin{array}{l}0.703088 \\
(0.9177445)\end{array}$ & 0.77 & 0.446 \\
\hline Age & $\begin{array}{l}0.2583445 \\
(0.3141236)\end{array}$ & 0.82 & 0.414 \\
\hline Age $^{2}$ & $\begin{array}{l}-0.0033861 \\
(0.0032557)\end{array}$ & -1.04 & 0.302 \\
\hline Marital status & $\begin{array}{l}2.666231 \\
(0.6823709)\end{array}$ & 3.91 & $0.000^{*}$ \\
\hline Education & $\begin{array}{l}0.64175750 \\
(0.2458841)\end{array}$ & 2.61 & $0.005^{*}$ \\
\hline Ethnicity & $\begin{array}{l}2.38709 \\
(0.8533534)\end{array}$ & 2.80 & $0.007^{*}$ \\
\hline Religion & $\begin{array}{l}0.6141613 \\
(0.5978697)\end{array}$ & 1.03 & 0.308 \\
\hline Experience & $\begin{array}{l}0.0248966 \\
(0.0526089)\end{array}$ & 0.47 & 0.638 \\
\hline Credit access & $\begin{array}{l}0.8244234 \\
(0.4705805)\end{array}$ & 1.75 & $0.084^{* *}$ \\
\hline Membership & $\begin{array}{l}1.738994 \\
(0.4246139)\end{array}$ & 4.10 & $0.000^{*}$ \\
\hline Association & $\begin{array}{l}0.00000233 \\
(0.000000597)\end{array}$ & 3.90 & $0.000^{*}$ \\
\hline Machine replacement & & & \\
\hline
\end{tabular}

\section{$\mathbf{R}^{2}=0.5156$. $\quad$ F-statistic $=7.13$, Prob $>\mathbf{F}=0.0000$ \\ *significant at $1 \%$,** significant at $10 \%$. \\ Source: Field Survey, 2015.}

\section{Conclusion and Recommendations}

The study attempted to examine the effect of machine replacement cost on the profitability of feed mill industries in Oyo state, Nigeria. The results of the study revealed that the hammer mill/grinder, mixer and scale were the prominent machines used by feed millers in the area. The machines had an average age of six years expect for scale which had an average of five years. The result also revealed a positive relationship of machine replacement cost with profitability of feed mill which implies that as the profit increases, machine replacement cost also increases. The reason may be attributed to the fact that as the feed mill produces more feed, machines tend to experience breakdown or wear out due to over use. This in turn increases the maintenance cost as well as the replacement cost. However, prompt replacement of machines would promote increased efficiency in production. The study therefore recommends adequate maintenance and timely replacement of machine as they have significant influence on profitability of feed mills.

\section{References}

[1]. Ademuyiwa M.A, Gbenga T.A and Lawrence A.A (2014): Economic Analysis of feedmill industries in Ogun and Oyo State, Southwestern of Nigeria. Research Journalis Journal of Entrepreneurship Vol 2, No 2 pp 2-10.

[2]. Ademuyiwa M.A. (2004): Economic Analysis of Feed mill in Nigeria: Final thesis for MBA: university of Agriculture Abeokuta.

[3]. Akinnuli, B.O. (2009): Development of models for machinery evaluation in manufacturing industries (unpublished doctoral dissertation). The Federal University of Technology Department of Mechanical Engineering, Akure, Nigeria.

[4]. Akinuli, B.O. (2011): Computer- aided system for modeling machinery procurement due - date Failure of Tool Machine Elements." Tribology in industry, volume 32 , No. 3

[5]. Akinuli, B.O. (2014): Modification and Application of industrial Machinery optimum replacement model. Research Journal in Engineering and Applied Sciences Vol 3, No 3 pp 191-198.

[6]. Bamaiyi P.H (2013): Factors Militating Against Animal Production in Nigeria. International Journal of Livestock Research Volume 3, No 2 pp 53-66.

[7]. Bethuyne, G. (1998): "Optimal Replacement under Variable Intensity of Utilization and Technological Progress." The Engineering Economist, vol. 43, No.2, pp. 85- 106.

[8]. Esplana E.R and Soliaban C.L (2005): Dynamics of the Philippine Feedmill Industry: An assessment. Accessed online www.smileyberks.com/cpr on $8^{\text {th }}$ September, 2015.

[9]. Gupta, P.K and Hira D.S (2012). "Replacement models, Operations research Revised Edition, chand and company Ltd, Ram Nager, New Delhi, pp $994-1035$.

[10]. Odunsi, A.A, Akande, T.O, and Rafiu T.A. (2008): Understanding Practical Poultry and Feed Mill Management. Ola Printers, Ogbomoso. Revised Edition. Pp 28 - 31.

[11]. Oladejo, J.A (2012): Economic Analysis of feedmill in Lagos State, Nigeria. International Journal of Research in Management, Economics and Commerce Vol 2 issue 2 pp 39-52.

[12]. Olayemi and Onyenwaku (1999): Operation Research, A publication of the department of Agricultural Economics, University of Ibadan, Ibadan, Nigeria.

[13]. Tadic, B.,vukelic, D., and Jeremic, B. (2010):"Defining a Theoretical Model of Wear - Caused prediction in production industries. Journal of ICT, 10, Pp $99-115$, Malaysia.

[14]. Uba, G (2013): Investing in Animal feeds and fish meal Production. Retrieved online www.thisdaylive.htm. $25^{\text {th }}$ September, 2015 